\title{
Utrecht 1996 Annual Conference
}

Everything seems to proceed smoothly and efficiently and the theme looks more interesting and challenging than ever! Prof. Paul Schnabel, dean of the Netherlands School of Public Health, our organising host, is very enthusiastic about the conference. The first announcement was mailed at the end of March.

The Executive Board and the Organising Committee have finally decided that the conference will in fact start on Saturday the 26th in the early afternoon, through special interest groups meeting.

Among them, the Executive Board wanted to have a special meeting for the directors of departments of Public Health and for the deans of Schools of Public Health; the topic will be: the schools and their association. I come back from a visit to our sister organisation in the USA where I notably prepared their contribution to this event. The other "regional" associations will also be invited.

A second special ASPHER workshop will take place on Monday 28, devoted to new developments in the missions and organisation of training institutions in Public Health in Europe, and will be open to all participants.

Details will be approved by the Executive Board of May 3, 1996.

Prof. Louise Gunning-Schepers has accepted to chair the scientific committee, which is particularly appropriate due to her special expertise in the general theme of the conference.

As you may remember, the theme will be "Inequity in Health, the role of Schools of Public Health".

Apart from a few stimulating key-speakers, seven sub-themes workshops will be organised; the call for papers will come to you alongside the first announcement.

The possibility will be open for those who want to take advantage of the ASPHER gathering to organise a "parallel" workshop around the annual conference. Agreement has to be obtained both from the local organiser for availability of rooms and from ASPHER for announcement purposes and in order to guarantee these meetings are not in contradiction with the general mission or the common interests of the association. In practice, requests should be sent to the organising committee, on which I participate.

A clear identification of the purpose, the participants and especially the person in charge will be definitely required.

Best time slots will be on Saturday October 1996 or Tuesday October 29, eventually Wednesday October 30.

Jacques A. Bury

\section{ASPHER Masthead}

The ASPHER Bulletin is published twice a year both as a supplement to the Zeitschrift für Gesundheitswissenschaften/Journal of Public Health and for its members and others interested in European public health training. Circulation: 500 copies.

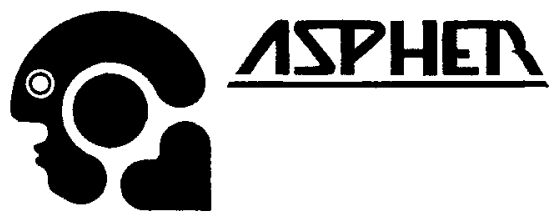

\section{Bulletin}

Evelyne de Leeuw, ASPHER, PO Box 616, 6200 MD Maastricht, The Netherlands fax +31433670932

ASPHER Office

14, Rue du Val d'Osne, 94415 Saint Maurice Cedex, France fax +33143966463

Zeitschrift für

Gesundheitswissenschaften

Juventa Verlag, Ehretstraße 3, 69469 Weinheim, Germany

fax +49620113135
Z. f. Gesundheitswiss., 4. Jg. 1996, H. 3 